\title{
Marital Satisfaction and General Happiness among urban Malays in Klang Valley
}

\author{
Suzana Mohd Hoesni, Siti Marziah Zakaria
}

\begin{abstract}
Marital satisfaction is a mental state that induces a married individual to feel happy regarding in his or her married life. Therefore, this study was conducted to identify the background factors of married urban Malays and to determine the relationship between marital satisfaction and general happiness among urban married Malay individuals. This study employs an exploratory design using survey method in the form of questionnaire. Each questionnaire contains a set of questions and measurement tools to gather background information, the level of marital satisfaction and general happiness of the respondents. A total of 421 respondents who were Malays and have been married for at least a year, and resided in the Klang Valley area participated voluntarily in this study. In general, this study found that there were positive and significant relationships between general happiness and factors namely marital satisfaction ( $k$ $\left.<0.01, r=0.466^{* *}\right)$, age $\left(k<0.01, r=0.148^{* *}\right)$, individual monthly income $\left(k<0.05, r=0.118^{*}\right)$, family income $(k<0.05, r=0.113 *)$, length of marriage $\left(k<0.05, r=0.114^{*}\right)$ and age of the eldest child ( $k<0.01, r=0.137 *$ ). The outcome of this study suggests the importance of marital satisfaction in elevating the general happiness of married individuals. Besides that, religious beliefs and values were also found important in achieving marital satisfaction. Suggestions for future researchers and members of the helping profession like counselors, therapists and social workers working with married couples who specifically adhere to certain values and cultures were also discussed.
\end{abstract}

Keywords: marital satisfaction, general happiness, Malays, urban, culture.

\section{INTRODUCTION}

Marital satisfaction is one of the psychological aspects studied by researchers in the field of marriage to understand happiness of an individual in his or her marriage [1-4]. Marital satisfaction is studied because of its importance and relation to the psychological well-being of an individual in his or her life.

The state of happiness achieved allows an individual to continue performing his or her role in daily life. This harmonious situation is not only a necessity for married individuals but also very essential in meeting every challenge of daily life. Those challenges include matters related to the way they communicate, implement religious values and beliefs, make decisions and resolve financial-related matters, sexuality, parenting, and interact with in-laws.

Revised Manuscript Received on September 25, 2019 Suzana Mohd Hoesni, Senior Lecturer in UKM, Malaysia. Siti Marziah Zakaria, Senior Lecturer in UKM, Malaysia.
Happiness in a marriage enables married individuals to perform their functions and roles in life. The importance of achieving happiness in a marriage has become more vital as every marriage comes with the responsibility of nurturing and taking care of other persons. Those persons include children and/or other members of the family. The process of socialization could be accomplished perfectly if the psychological state of the married individual was fulfilled. Difficult situations could be eased if a safe and harmonious environment existed. [5],[6]. To put it another way, if a peaceful condition was not realized, not only the married individual would be negatively affected but it might also have the same effect toward his or her children and other members of the family [7],[8],[9]. A harmonious atmosphere must be created in marriage to facilitate married individuals and other family members in achieving happiness in life and optimizing their potentials. Likewise, a happy marriage indirectly contributes to the well-being of the family.

Consequently, the researchers would like to find the answers to these following questions: 1) What are the background factors, the level of marital satisfaction and general happiness among married urban Malays? and 2) What is the relationship between marital satisfaction and general happiness among married urban Malays? In this study, the researchers will focus on the common factors leading to marital satisfaction and happiness in life. The concept of marital satisfaction in this study encompasses married individual's personalities and habits, how married individuals handle responsibilities in the family, communication, decision-making, problem-solving, finances, how time is spent together with spouse, romance and sexuality, parenting, relationships with parents, in-laws, and friends, and practicing religion and its values. Whereas, general happiness covers both positive and negative affect among married Malays.

\section{PROCEDURE FOR PAPER SUBMISSION}

\section{A. Design of study}

This study employs an exploratory research design using survey method in the form of a questionnaire. There are three main parts of the questionnaire. The first section consisted of questions related to respondents' background. The second part poses questions about the marital satisfaction of the respondents. Meanwhile, questions in the third part are related to the general happiness of the respondents.

B. Sampling and procedure

Sample size was determined with the help of online survey calculator gained from

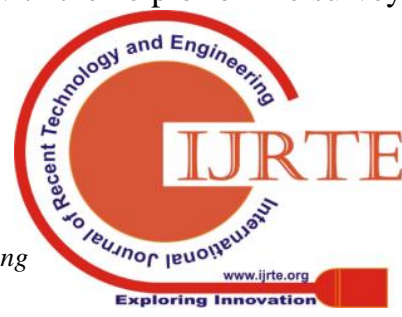


http://www.surveysystem.com/sscalc.htm. Sampling was executed by determining the confidence interval and confidence level to the online calculator. Researchers determined the confidence interval as " 5 " and confidence level at $95 \%$. A total of 384 individuals were suggested as sample for this study. However, in order to ensure the questionnaires were free from missing values and chances of low return rate, researchers decided to have 450 as sample size.

This study applied a combination of the simple random sampling and the multistage cluster sampling. First, a list of 261 governmental bodies were identified using the list as found in http://www.lib.upm.edu.my/bm/mfed.html. Only organizations within Federal Territory were chosen for this study. Simple random sampling was executed using the "tombola method. Each of the listed organizations was provided with a small piece of paper with the name of that organization and those papers were then placed in a container. Next, the researchers selected 30 organizations to form the sample population for this study. Only individuals living in the Federal Territory were selected for this study. The researchers contacted the resource management department of the organizations selected to inform them about this study.

Upon approval, a representative from the organization would distribute the questionnaires to the respondents. The researchers had conducted visits to the selected organizations and presented the written consent permitting them to conduct the study. A total of 15 sets of questionnaires were presented to the representative of the respective organization. Each representative was informed of the requirements of this study and the questionnaires were handed over to the representative and they had to be completed within a specified period of time. A total of 421 fully completed questionnaires were returned and collected by the representatives and then compiled by the researchers

\section{Questionnaire}

The questionnaire in this study consists of three (3) sections. Section A comprises questions related to respondents' background. Section B consists of questions related to marital satisfaction. Section $\mathrm{C}$ contains questions related to general happiness.

\section{Section A: Demography}

Questions in this section serve the objective of describing the respondents involved in this study. To be more specific, those questions are related to respondents' background namely gender, age, race, religion, education level, monthly income, household income, length of marriage, number of children and finally, age of the eldest and youngest child.

\section{Part B: Marital Satisfaction}

The process of measuring marital satisfaction in this study utilizes 10 items from ENRICH Marital Satisfaction Scale (EMS) [10]. The 10 items cover questions which include spouses' personalities, roles and responsibilities, communication, decision-making and problem-solving, financial-related decision-making, how they spend time together, sexual matters, parenting, relationships with in-laws and how they practice religious values. Respondents state their answers in 5-point Likert scale type responses $(1=$ strongly disagree and $5=$ strongly agree). A higher score indicates higher marital satisfaction while a lower score identifies with lower marital satisfaction. The maximum score is 50 and the score of 10 is the lowest on the marital satisfaction scale. The validity of this test tool is good and has been widely used in the field of marriage research. Among the studies that have used this test tool were confirmatory factor analysis [11], sexual dysfunction [12] and couple satisfaction and stability [13]. The reliability of the measurement tool in this study is also good at $.87(\alpha=.87)$. This exceeds the Cronbach's minimum alpha level of .70 as suggested by [14].

\section{Part C: General Happiness}

General happiness in this study is measured using the Affective Balance Scale (ABS) developed by Bradburn [15]. This scale has 10 items in which five (5) items measure the positive affective and five (5) items calculate the negative affective. Responses to this measurement tool are dichotomous or two answer choices, namely $1=$ "yes" and $2=$ "no". A higher score indicates a happier individual. The validity of this test tool is good and has been widely used in the field of psychological research related to happiness. These include studies specifying on the validity of measuring tools such as convergent validity [16], confirmatory factor analysis [17],[18] and studies using sample population involving family and caregivers [19]. The reliability of this test tool is also good. The KR-20 test was conducted as recommended by Novick, (1968) [20], [21] in testing the reliability of a dichotomous test instrument. As a whole, the reliability of this test tool is .71 and it exceeds the level suggested by [14] and [22].

\section{RESULTS}

Results of this study is divided into two main aspects. First is the outcome of the descriptive analysis to describe the respondents involved. In addition to that, the inference analysis determines the relationship between the factors related to respondents' general happiness.

\section{A. The outcome of descriptive analysis}

As shown in Table 1a, a total of 421 individuals comprising 133 men $(31.6 \%)$ and 288 women $(68.4 \%)$ were involved in this study. All respondents who participated in this study were Malays and Muslims. Most respondents have Bachelor's degrees $(36.1 \%)$ followed by respondents with the Malaysian Certificate of Education (MCE) (25.2\%). The least number of respondents $(0.2 \%)$ had attended or completed primary school.

Table 1a) Respondent's background factors

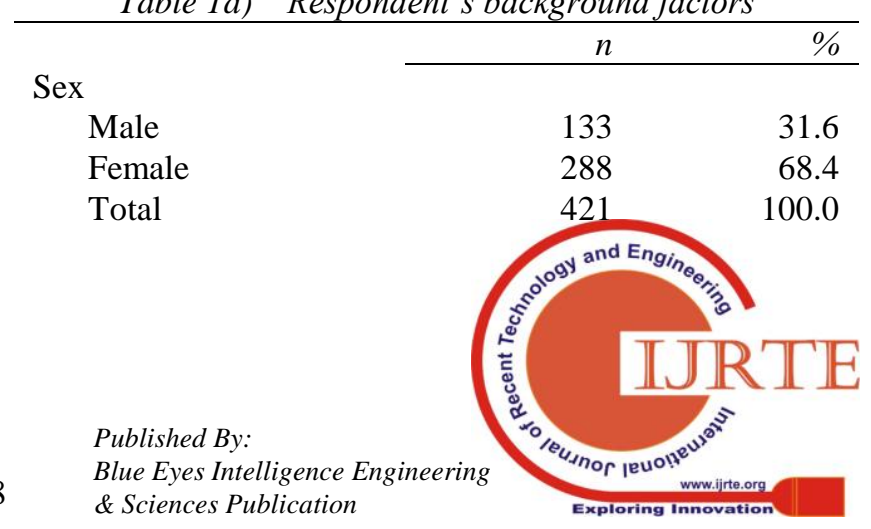




\begin{tabular}{|c|c|c|c|c|c|c|c|c|}
\hline Malays & 421 & 100 & Age of eldest & 421 & .08 & 33 & 9.84 & 7.90 \\
\hline Total & 421 & 100 & child & & & & & \\
\hline Religion & 421 & 100 & $\begin{array}{l}\text { Age of } \\
\text { youngest }\end{array}$ & 421 & .08 & 24 & 5.00 & 5.39 \\
\hline Islam & 421 & 100 & child & & & & & \\
\hline
\end{tabular}

This study also discovered factors that has the highest level

Level of Education

Primary school

SRP/PMR

SPM

STPM

Diploma

Bachelor

Masters

$\mathrm{PhD}$

Others

Total

Number of children

$\begin{array}{lrr}0 & 76 & 18.05 \\ 1 & 90 & 21.38 \\ 2 & 108 & 25.65 \\ 3 & 95 & 22.57 \\ 4 & 39 & 9.26 \\ 5 & 13 & 3.09 \\ \text { Total } & 421 & 100.0\end{array}$

Table 1b) shows

Table $1 \mathrm{~b}$ ) shows age of respondents ranged from 20 to 61 years with an average age of 35.32 years and a standard deviation of 8.49 years. The average monthly income of the respondents is $\mathrm{RM} 3,053.00$ with a standard deviation of $\mathrm{SD}=$ RM2,039.40. The lowest monthly income is RM450 and the highest is RM15,000.00. Household income ranges from RM600 to RM35,000 with an average of RM6,370.00 per month with a standard deviation of SD $=\mathrm{RM} 4,490.50$. The average length of marriage is 9.7 years with a standard deviation of SD $=8.30$ years. The range of respondents' length of marriage is from .08 to 36 years. Most respondents have two children $(25.65 \%)$. They are followed by respondents having three children $(22.57 \%)$ and a single child $(21.38 \%)$. About $18.5 \%$ of the respondents are childless. Besides, the age of respondents' eldest child ranges from .08 to 33 years. The mean age of the eldest child is 9.84 years with a standard deviation of $\mathrm{SD}=7.90$. Their ages range from .08 to 24 years. The mean age of respondents' youngest child is 5.00 years with a standard deviation of $\mathrm{SD}=5.39$ years.

Table 1b) Respondent's background factors

\begin{tabular}{lrrrrr}
\hline & $N$ & Min & Max & $M$ & $S D$ \\
\hline Age & 421 & 20 & 61 & 35.32 & 8.49 \\
$\begin{array}{l}\text { Monthly } \\
\text { salary }\end{array}$ & 421 & 450 & 15000 & 3053.0 & 2039.4 \\
$\begin{array}{l}\text { Household } \\
\text { income }\end{array}$ & 421 & 35000 & 6370.2 & 4490.5 & 4490.5 \\
$\begin{array}{l}\text { Length of } \\
\text { Nent }\end{array}$ & 421 & .08 & 36 & 9.70 & 8.30
\end{tabular}

Marital satisfaction in this study covers the aspects of spouses' personality traits, roles and responsibilities shared between spouses, communication, decision-making, and problem-solving, financial-related decision-making, how respondents spend their time together, sexual matters, parenting, relationship with in-laws and the approach taken in implementing religious values. The study also realizes the aspects considered the most important are matters

On the whole, it is found that marital satisfaction is one of the most important factors concerning the general happiness of the respondents. 
related to religious values and beliefs and followed by how individuals and spouses exercise their roles and responsibilities.

Similarly, the respondent's background especially his or her age and the age of his or her eldest child is found to be closely related to the general happiness of an individual. In other words, the older the individual, the more likely the married person to achieve general happiness. This could be attributed to the increase in age and maturity as well as the experience of so many incidents in life which in turn, might help the individual to behave maturely when facing the challenges of everyday life.

The increasing age of the eldest child is also associated with the general happiness of an individual. To rephrase, the older the age of the eldest child, the greater the probability for an individual to achieve general happiness. This observation may be attributed to the lighter responsibility faced by an individual as he or she no longer needs to provide a great deal of attention to a child who is growing more independent.

The study also learns that one of the most important factors taken into consideration in achieving marital satisfaction is how individuals perceive the consensus in practicing religious values and beliefs. In a marriage, cultural factors concerning individuals such as religious values and beliefs are found to be important in elevating marital satisfaction which in sequence, leads to general happiness. As discovered by the study, the key factors are matters related to religion, values, and beliefs. The scenario may be different in cultures other than Malay and Islam. Therefore, this situation needs to be attended by members of the helping profession such as counselors, social workers, and therapists working with clients who are married and have families. They need to be sensitive to this kind of situation when working with such clients since most existing theories and modules on marriage are originated from the West.

\section{CONCLUSION}

To conclude, this study demonstrates how important it is for studies on marriage and psychological well-being to focus on specific aspects of a particular culture. It also suggests the need for deeper research to help enrich the understanding of marriage and family issues in a particular culture. This finding not only contributes to the field of psychology that focuses on interpersonal and close relationships specific to a particular culture, but it also provides a perspective in contributing to the field of helping profession involving counselors, social workers and marriage therapists in assisting clients who are married and have families.

\section{REFERENCES}

1. Asoodeh, M. H., Khalili, S., Daneshpour, M., Lavasani, M. G. 2010. Factors of successful marriage: Accounts from self-described happy couples. Procedia-Social and Behavioral Sciences. 5:2042-2046

2. Dinani, P.T., Zarbakhsh, M., Samkhaniyan, E., Hamidi, M and Arkiyan, F. (2014). Study on the relationship between love attitudes and marital satisfaction among married women. European Online Journal of Natural and Social Sciences, 3(3), 468-474.

3. Bradbury, T.N., Fincham, F.D., \& Beach, S.H. 2000. Research on the nature and determinants of marital satisfaction, a decade in review. Journal of Marriage and Family, 62, 964-980
4. Williamson, H.C., Nguyen, T.P., Bradbury, T.N. \& Karney, B.R (2015). Are problems that contribute to divorce present at the start of marriage, or do they emerge over time? Journal of Social and Personal Relationships, 33 (8), 1120-1134.

5. Knopp, K., Rhoades, G. K., Allen, E. S., Parsons, A., Ritchie, L. L., Markman, H. J., \& Stanley, S. M. (2017). Within and between family associations of marital functioning and child well-being. Journal of Marriage and Family, 79(2), 451-461.

6. Buehler C., Krishnakumar, A., Stone G., Anthony, C., Pemberton, S., Gerard, J. \& Barber, K. 1998. Interparental conflict styles and youth problem behavior: A two-sample replication study. Journal Of Marriage And The Family, 60: 119-132

7. Ahmadi, K., \& Hossein-abadi, F. (2009). Religiosity, marita satisfaction and child rearing. Pastoral Psychology, 57(5/6): 211-221.

8. Aluja Anton, del Barrio Victoria \& García Luis F. (2007). Personality, social values, and marital satisfaction as predictors of parents' rearing styles. International Journal of Clinical and Health Psychology, 7(3): 725-737.

9. Katz, L. F., \& Gottman, J. M. (1993). Patterns of marital conflict predict children's internalizing and externalizing behaviors. Developmental psychology, 29(6), 940.

10. Fowers, B. J., \& Olson, D. H. (1993). ENRICH Marital Satisfaction Scale: A Brief Research and Clinical Tool. Journal of Family Psychology, 7(2), 176-185. DOI: 10.1037/0893-3200.7.2.176

11. Fowers, B.J. \& Applegate, B. (1995). Do Marital Conventionalization Scales Measure a Social Desirability Response Bias? A Confirmatory Factor Analysis. Journal of Marriage and Family, 57(1), 237-241.

12. Ahmadi, K., Ranjebar-Shayan, H. \& Raiisi, F. (2007). Sexual dysfunction and marital satisfaction among the chemically injured veterans. Indian Journal of Urology, 23(4), 377-382.

13. Vanderbleek, L.,Robinson, E.H.,Casado-Kehoe, M. \& Young, M.E. (2011). The Relationship Between Play and Couple Satisfaction and Stability. The Family Journal, 19(2), 132-139.

14. Loewenthal, K.M. (2001). An introduction to psychological tests and scales: 2nd edition. Philadelphia: Psychology Press Ltd.

15. Bradburn, Norman M. The Structure of Psychological Well-Being Chicago: Aldine, 1969. Table: The distribution of avowed happiness in selected studies, 40. Table: Coefficients of association among indicators of social participation, 126.

16. Lewis, McCollam \& Joseph (2000). Convergent Validity Of The Depression-Happiness Scale With The Bradburn Affect Balance Scale. Social Behavior And Personality: An International Journal. 28(6), 579-584.

17. Helmes, Goffin \& Chrisjohn (2010). Confirmatory Analysis of the Bradburn Affect Balance Scale and its Relationship with Morale in Older Canadian Adults. Canadian Journal on Aging, 29(2), 259-266.

18. Macintosh, R. (1998). A Confirmatory Factor Analysis of the Affect Balance Scale in 38 Nations: A Research Note. Social Psychology Quarterly, 61(1), 83-95.

19. Perkinson, Albert, Luborsky, Moss \& Glicksman (1994). Exploring the validity of the Affect Balance Scale with a sample of family caregivers. Journal of Gerontology, 49(5), 264-275.

20. Lord, F.M, \& Novick, M.R. (1968). Statistical Theories of Mental Test Scores. Reading MA: Addison -Wesley.

21. Traub, R.E. (1994), Reliability for the Social Sciences: Theory and Applications. Thousand Oaks CA: Sage.

22. Pallant, J. (2016). SPSS Survival Manual: A Step By Step Guide to Data Analysis Using SPSS Program (6th ed.). London, UK: McGraw-Hill Education. 


\section{AUTHORS PROFILE}

Suzana Mohd Hoesni (PhD in Psychology). Her expertise is in developmental psychology focusing on interpersonal relationships with special interest in marriage and love. She is a senior lecturer in UKM, Malaysia.

Siti Marziah Zakaria (PhD in Psychology). Her expertise is in developmental psychology, life satisfaction, emotional well being and women empowerment. She is a senior lecturer in UKM, Malaysia. 